\title{
Design of a medication management program for Medicare beneficiaries: Qualitative findings from patients and physicians
}

\author{
Julie C. Lauffenburger, PharmD[Doctoral Student] \\ Division of Pharmaceutical Outcomes and Policy, UNC Eshelman School of Pharmacy, University \\ of North Carolina at Chapel Hill Chapel Hill NC
}

\section{Maihan B. Vu, DrPH, MPH[Director of Formative Research] \\ Center for Health Promotion and Disease Prevention, University of North Carolina at Chapel Hill, Chapel Hill NC

\begin{abstract}
Jena Ivey Burkhart, PharmD, BCPS[Clinical Assistant Professor]
Division of Pharmacy Practice and Experiential Education, UNC Eshelman School of Pharmacy, University of North Carolina at Chapel Hill Chapel Hill NC
\end{abstract}

\section{Morris Weinberger, PhD[Professor of Health Policy and Management] \\ UNC Gillings School of Global Public Health, University of North Carolina at Chapel Hill, and Senior Research Career Scientist, Durham VAMC Center of Excellence in Health Services Research}

\section{Mary T. Roth, PharmD, MHS[Associate Professor] \\ Division of Pharmaceutical Outcomes and Policy, UNC Eshelman School of Pharmacy, University of North Carolina at Chapel Hill Chapel Hill NC}

\section{Abstract}

Background-The quality of pharmacologic care provided to older adults is less than optimal. Medication therapy management (MTM) programs delivered to older adults in the ambulatory care setting may improve the quality of medication use for these individuals.

Objectives-We conducted focus groups with older adults and primary care physicians to explore: (1) older adults' experiences working with a clinical pharmacist in managing medications, (2) physician perspectives on the role of clinical pharmacists in facilitating medication management, and (3) key attributes of an effective MTM program and potential barriers from both patient and provider perspectives.

\begin{abstract}
Methods-Five focus groups ( 4 with older adults, 1 with primary care physicians) were conducted by a trained moderator using a semi-structured interview guide. Each participant completed a demographic questionnaire. Sessions were recorded, transcribed verbatim, and analyzed using qualitative analysis software for theme identification.
\end{abstract}

\footnotetext{
(C) 2012 Excerpta Medica, Inc. All rights reserved

Corresponding author: Julie C. Lauffenburger, PharmD, Doctoral Student, Division of Pharmaceutical Outcomes and Policy, UNC Eshelman School of Pharmacy, University of North Carolina at Chapel Hill Chapel Hill NC Postal address (for reprints): CB 7573, UNC Eshelman School of Pharmacy, Chapel Hill NC 27599 Phone number: 412-979-7077 Fax number: 919-966-8486 jlauffen@unc.edu.

Publisher's Disclaimer: This is a PDF file of an unedited manuscript that has been accepted for publication. As a service to our customers we are providing this early version of the manuscript. The manuscript will undergo copyediting, typesetting, and review of the resulting proof before it is published in its final citable form. Please note that during the production process errors may be discovered which could affect the content, and all legal disclaimers that apply to the journal pertain.
}

CONFLICT OF INTEREST The authors indicate that there are no conflicts of interest related to the contents of this study. 
Results-Twenty-eight older adults and 8 physicians participated. Older adults valued the professional, trusting nature of their interactions with the pharmacist. They found the clinical pharmacist to be a useful resource, thorough, personable, and a valuable team member. Physicians believe the clinical pharmacist fills a unique role as a specialized practitioner, contributing meaningfully to patient care. Physicians emphasized the importance of effective communication, pharmacist's access to the medical record, and a mutually-trusting relationship as key attributes of a program. Potential barriers to an effective program include poor communication and lack of familiarity with the patient's history. The lack of a sustainable reimbursement model was cited as a barrier to widespread implementation of MTM.

Conclusions-This study provides information to assist pharmacists in designing MTM programs in the ambulatory setting. Key attributes of an effective program include one that is comprehensive, addressing all medication-related needs over time. The clinical pharmacist's ability to build trusting relationships with both patients and providers is essential.

\section{Keywords}

older adults; medication management; focus groups; collaborative practice; pharmacists

\section{INTRODUCTION}

The overuse, underuse, and misuse of medications contribute to the sub-optimal quality of care delivered to Americans. ${ }^{1-3}$ Older adults are at increased risk for poor quality of medication use because multiple medications are often required for numerous chronic diseases and are prescribed in an uncoordinated fashion by multiple providers. ${ }^{4-6}$ The poor quality of medication use may account for almost $75 \%$ of all hospitalizations by older adults in the United States. ${ }^{7,8}$ Thus, the health and well-being of older adults in the United States relies on the appropriate prescribing of medications by health care providers as well as the proper use and management of medications by patients.

The quality of medication use has been shown to be improved through outpatient management that emphasizes appropriate medication use. ${ }^{9,10}$ However, to be effective, health information must be shared and care must be coordinated among all providers and patients. ${ }^{11}$ The federal government has recognized significant deficiencies in the care delivered to older adults regarding medication use and has begun to align payment incentives for pharmacists and others to provide medication therapy management (MTM) to Medicare beneficiaries. ${ }^{12}$ Although MTM programs represent a promising approach to reducing medication-related morbidity, mortality and unnecessary health care utilization, studies are needed to identify the most effective and feasible models for delivering MTM services. ${ }^{9,13,14}$ In particular, MTM programs offered in the ambulatory setting will be critical to the development of the collaborative patient-centered medical home (PCMH). To this end, we conducted a qualitative study to gain insights into the design and feasibility of medication management services offered by clinical pharmacists from patients and primary care physicians. These data will be used to design and evaluate an MTM program for older adults receiving care within a physician-based outpatient clinic.

\section{Objectives}

We conducted focus groups with older adults and primary care physicians to explore: (1) older adults' experiences working with a clinical pharmacist in managing their multiple medications, (2) physician perspectives on the role of clinical pharmacists in facilitating medication management, and (3) key attributes of an effective MTM program and potential barriers from the perspective of both patients and providers. 


\section{PATIENTS AND METHODS}

\section{Overview of Study Design}

Qualitative methods were chosen for their utility in exploring the topic from the perspective of older adults and physicians, garnering richer data than quantitative methods may yield. ${ }^{15}$ Focus groups allow researchers to derive information through communication between participants as well as allow for flexibility in exploring issues and still maintain internal study validity. ${ }^{15}$ Thus, we conducted 5 focus groups: 4 with older adults and 1 with primary care physicians. Our goal was to recruit 8-12 participants for each group, which is ideal for generating discussion and allowing all participants sufficient opportunity to speak. ${ }^{16,17}$ The number of focus groups was determined a priori for both patient and physician groups. Study investigators felt that saturation would likely be reached after approximately 4 sessions with older adults and obtaining feedback from at least 1 group of physicians would be sufficient to meet our needs for the purpose of designing an initial intervention. This study was approved by the University of North Carolina at Chapel Hill Institutional Review Board.

\section{Participants}

Older adults were eligible for the study if they were aged $\geq 60$ years; taking $\geq 5$ prescribed medications; residing independently in Orange County, NC; responsible for managing their own medications (without reliance on a caregiver or family member); and either of white or black race.

Physicians were eligible if they practiced in an outpatient setting in Orange County, NC; provided care to individuals $\geq 60$ years of age; and had experience working with a clinical pharmacist. We felt that the design of the MTM program would best be informed by physicians who had experience working with pharmacists in such a program.

\section{Recruitment and Enrollment}

Older Adults-We identified a convenience sample of older adults from a registry of patients enrolled in the Eldercare Program through the Orange County Department on Aging and two senior housing facilities located in Chapel Hill, NC. ${ }^{18}$ The Eldercare Program provides social services and case management to nearly 300 older persons residing independently in their own homes, apartments, or senior housing. Both senior housing complexes are affiliated with the Eldercare Program. We purposively sampled older adults with mixed degrees of exposure to clinical pharmacist services to ensure that we were reaching a wide audience, which ranged from those having episodic encounters with a clinical pharmacist to those receiving continuous care with an ongoing relationship with the clinical pharmacist. Participants were contacted by a pharmacist using a telephone script until 8-12 eligible older adults were reached who expressed an interest in participating.

Physicians-We purposively sampled physicians in Orange County from diverse outpatient clinic settings (e.g., academic medical center ambulatory care clinics, geriatric specialty outpatient clinics, community-based private physician clinics, family medicine clinics, federally qualified health programs) until 8 eligible physicians were reached who expressed an interest in participating.

\section{Focus Group Methodology}

Four focus groups with older adults were held between October and December 2008 at a local senior center; one focus group with physicians was held in February 2009 at the UNC Eshelman School of Pharmacy. All focus groups were approximately 90 minutes. Prior to 
each session, participants completed informed consent and a demographic questionnaire. Each session was moderated by a trained, experienced qualitative researcher (MV) to minimize bias and ensure that all participants were provided an opportunity to speak and provide input. In addition, all sessions were recorded using a digital voice recorder. To maintain consistency, the same moderator conducted all focus groups using a semistructured interview guide developed by the investigators (Appendix); one interview guide for the older adult group, one for the physician group. Both focused on the same study objectives, but were tailored to the audience.

In the older adult groups, the discussion focused on 1) older adults' experiences managing their multiple medications, specifically as it related to working with a clinical pharmacist in managing their multiple medications and 2) gathering feedback from older adults on a proposed MTM program. Participants received a $\$ 30$ honorarium, light snacks during the focus group discussion, and the opportunity for a free medication review with a clinical pharmacist following the session. In the physician group, the discussion focused on 1) experiences working collaboratively with clinical pharmacists in the outpatient, ambulatory setting, and 2) obtaining physician input into a proposed MTM program for older adults. Each physician received a $\$ 100$ honorarium and dinner during the focus group discussion. At the start of each focus group session, the moderator introduced the study, briefly explained the objectives of the session, and opened the session with an icebreaker. In all groups, participants were encouraged to respond to any issues raised by the moderator but were not forced to respond. The moderator sought to engage all participants, avoid the discussion being dominated by a single individual, and minimize interjection.

\section{Data Collection and Analysis}

All focus groups were audio-taped, transcribed verbatim, and analyzed using Atlas Ti qualitative data analysis software to identify themes through a Natural Language Processing method. ${ }^{16,17}$ The data collection and analysis was conducted by a trained, independent, qualitative researcher (MV). Group-to-group validation was performed to yield consistent themes in the groups. ${ }^{15,19}$

Once the data were analyzed, 3 investigators (JL, MV, MR) also reviewed the focus group findings several times to consolidate observations into a common set of themes, which were then agreed upon by the investigators. Disagreement was resolved through re-reading the transcripts together; using these multiple methods and investigators helps to avoid perception and blind interpretive bias. Key words and phrases were identified that provided descriptive information to support each theme. Verbatim quotations were identified that supported or further elaborated on an identified theme. Descriptive statistics were calculated for all variables collected as part of the demographic questionnaire.

\section{RESULTS}

Twenty eight older adults (Table 1) and 8 physicians (Table 2) participated in the focus groups. The findings from the focus groups are summarized according to the studies primary objectives: (1) older adults' experiences working with a clinical pharmacist in managing their multiple medications, (2) physician perspectives on the role of clinical pharmacists in facilitating medication management, and (3) key attributes of an effective MTM program and potential barriers from the perspective of both older adults and providers. Table 3 provides an outline of each of the three objectives along with the emerging themes and supporting key words and phrases. 


\section{Older Adults' Experience Working with a Clinical Pharmacist}

Older adults valued the professional nature of their interactions with clinical pharmacists. They found that the clinical pharmacist was a useful resource, with a wealth of knowledge about medications, including benefits of the medication, proper use, side effects, and drug interactions. They found the clinical pharmacist valuable, accessible, approachable, and personable. One participant referred to her clinical pharmacist as "really at the top of her game. She knows her stuff and is easy to get along with." They spoke, too, about the comprehensive nature of the interaction with clinical pharmacists, the time spent with them, the follow-up provided, and the attention given to their medications, which is "largely not available when interacting with a pharmacist in the community pharmacy setting." One patient stated "She has the knowledge and understands your overall health and knows the finer points." Older adult participants also felt that there were qualities in the clinical pharmacist that were different from, yet complementary to, their physician. Patients spoke about the clinical pharmacist complementing the medical care provided by the physicians, their ability to work well with their physicians and talk to them frequently. According to one patient, "Doctors are so busy, I don't think there is often time for that personal relationship. They open up a pill bottle and ask you how are things going and you say "ok."'

\section{Physician Perspectives on the Role of Clinical Pharmacists in Facilitating Medication Management}

Physicians in particular felt that the clinical pharmacist fills a unique role as a specialized, mid-level practitioner who enhances the connection with older patients around medication use. They cited a "personality" that feels comfortable talking to patients and providers alike. The positive attributes of a clinical pharmacist as characterized by physicians include: 1) the ability of pharmacists to see patients for targeted visits in between physician visits, 2) the time they are able to spend talking with the patients about their medications, 3) their excellent communication skills, and 4) their personality and approach to interacting with the patients. Specific physician comments supporting the above statements include:

"With diabetes management and care, I can schedule interval visits and if my schedule is full, I can have them come back in two weeks or three weeks and see the clinical pharmacist, get very specific instructions about diabetes management and then follow up with me in six weeks or eight weeks and so it's great for an interval visit with a very specific goals for that visit."

"I see the clinical pharmacist as having a special niche. Because of their detailed oriented training and medication management, they're much more fluent and immediately feel more comfortable with medicines. They can always come to me and so I think they fill a niche in our very complicated population..."

"There is a need to build a relationship of mutual trust between the clinical pharmacist and the physician so that the clinical pharmacist can understand the goals and approaches to treatment and the physician can have some knowledge of the clinical pharmacist's skills. I think that the more the program is sort of home based, the more interactions between the two, the more it can be effective."

"Our patients have an excellent relationship with the clinical pharmacist that runs the medication management clinic and I'm not so sure it's the position of clinical pharmacist. I really think personality, trust, and the personal interaction with the patients is kind of what is winning them over. I do think that other people in that position might not have the same level of success....it's a combination of the right personality and competence that wins them over and they look forward to seeing her...I think communication has been the key making that relationship a productive one." 
Physicians also noted potential areas of concern that they have encountered throughout the years when working with pharmacists. These include pharmacists who: 1) make recommendations when unfamiliar with the patient's history, 2) do not have access to or review the patient's medical record, 3) make medical and diagnostic assessments, 4) have an undefined role on a team or in the care of the patient, and 5) have poor communication with the physician.

"Sometimes I think the nuances of providing clinical care with multiple medications benefit from someone who has known that patient for a long time, knows their habits and ability to follow a particular regimen over a period of time and perhaps can see the bigger picture as to where we are going. Sometimes elderly patients with other co-morbidities, I'm not focused on that same A1C...There are also some patients that I know are going to be non-adherent so my goals are little bit different for them and sometimes it's frustrating for them to interact with the pharmacist who is not aware of these goals and it's also frustrating for the pharmacist to interact with the patients."

"The interaction is only effective if medical records are viewed first...that's what co-management, collaboration is about. That's where the two-way street happens, the relationship because that is how trust is built...because you are on the same page."

\section{Key Attributes of an Effective MTM Program and Potential Barriers from the Perspective of Patients and Providers}

Older adult participants identified the following as key attributes for the research team to consider in designing and implementing a medication management service:

- Team effort and trust: having a doctor and clinical pharmacist work together in a team effort on their behalf, entrusting all to do their part

- Personalized care: having a personal pharmacist - someone to assist with tasks such as reducing unnecessary medications, preparing a written list of all medications, or organizing the medications that need to be taken.

- Comprehensive: providing thorough medication reviews to assess effectiveness and safety; facilitating prescription refills; providing education around chronic care management and medications; assisting with Medicare Part D prescription drug plans.

Participants identified some of the potential problems with this type of program, including the availability of a pharmacist who would be willing to carry out such responsibilities and a perceived lack of need, in some patients, for any additional assistance with medication management. The issue of "cost to receive the service" was also a main concern for this program. While participants agreed it was a valuable service that they would be willing to pay for, the amount would have to be within their means. Participants suggested a "one-time payment for services in the format similar to insurance so that you can access the clinical pharmacist when needed, for as long as you need, with whatever you need."

Physician participants identified the following as key attributes for the research team to consider in designing and implementing a medication management service:

- A trusting relationship: the need to build a relationship of mutual trust between the clinical pharmacist and the physician so that the clinical pharmacist can understand the goals and approaches to treatment, the physician can be assured of the clinical pharmacist's knowledge and skills, and the benefit to the patient is maximized. 
- Communication and collaboration: effective communication and interaction between the clinical pharmacist and the physician; direct face-to-face interaction is key, not emails and faxes

- Patient-centered: clinical pharmacists must understand the social nuances of care and the people with whom they are interacting; medical records should be reviewed and time should be spent with the patient.

- Value-added: an effective MTM program should make the physician a better doctor. While physicians know some things about pharmacy, their interactions with clinical pharmacists should help them learn more. It should be a "value added" exchange so that physicians will be better equipped when treating other patients.

- Comprehensive: medication management should involve more than a medication review, with quality time spent, adequate follow-up, and medication reconciliation provided at the point of care transitions.

- Targeted: targeting certain populations, such as those with lower socioeconomic status, high comorbidity burden, and complex regimens are important considerations in designing a program.

Physicians identified some potential barriers to an effective program that should be considered when designing and implementing the service, including receiving too many recommendations, stating that "recommendations should be short and focused on priorities so that you don't overwhelm the receiver and hopefully have the highest chance of initiating some change". In addition, poor communication and providing services to those who may not need it were cited as potential barriers to successful implementation. Finally, payment for the services provided by clinical pharmacists was felt to be a significant barrier to widespread uptake and success. Physicians felt that a long-term, sustainable approach, beyond a fee-for-service model, is needed.

\section{DISCUSSION}

This study provides useful information from older adults and physicians regarding the defining characteristics of a clinical pharmacist and key attributes of an effective MTM program as well as potential barriers that must be considered in designing and implementing a program.

In summary, older adults reported that MTM services were valuable and meaningfully impacted their ability to manage medications. They specifically appreciated clinical pharmacists discontinuing unnecessary medications, providing a written list of medications, assisting with Medicare Part D prescription drug plan selection, and facilitating communication with their physicians. The physicians suggested that frequent and effective communication between the clinical pharmacist and physician is essential and that the program would be most effective when the number of recommendations are short and focused. In addition, physicians felt that the program would be most effective when pharmacists take the time to review the medical record and get to know the patients. It was felt that the program could be tailored or targeted to at-risk patients, including those on multiple medications or with multiple comorbidities. Older adults and physicians alike expressed the importance of building a trusting, professional relationship.

As has been reported in previous research, the absence of face-to-face communication and collaboration and "a trusting relationship" were viewed as potential barriers to successful implementation of an MTM program. ${ }^{20}$ Communication is critical to improving health outcomes; in addition, a trusting relationship is at the heart of the patient-physicianpharmacist relationship. ${ }^{21,22}$ 
Payment for clinical pharmacist's services was viewed as a potential barrier to widespread uptake. Despite the implementation of an MTM program in 2006 through Medicare Part D prescription drug plans and alignment of payment incentives this program continues to reach a minority of Medicare beneficiaries in need; is primarily delivered telephonically or via fax; does not provide a sustainable business model; and has demonstrated minimal impact to date. ${ }^{12,23}$ While some studies have demonstrated cost savings and improved outcomes with clinical pharmacist-delivered MTM services in ambulatory care settings, widespread reimbursement for such services is lacking. ${ }^{9,24}$ Bundled payments, where clinical pharmacist services are incorporated as part of a medical team approach and payment aligned to the team for the provision of high quality care is one potential approach to building a sustainable business model for clinical pharmacist-delivered MTM services.

These qualitative findings highlight the need to consider older adult and physician perspectives in the design of a MTM program.

\section{Limitations}

Our study had several limitations. First, although the size of our focus groups was typical $(8$ to 12 persons), our sample included 28 adults and 8 physicians in a specific region in North Carolina, which limits generalizability. The number of focus groups was typical; however, the number was determined a priori and not according to thematic saturation. The participants in the study were recruited via a convenience sample from a registry, thus limiting our reach to a more diverse population. However, the participants represented a variety of demographic characteristics and experience levels, thus we believe we captured a range of perspectives. Finally, patients and physicians often had experience with only one or two clinical pharmacists, which also may limit the generalizability of the findings. Future research of this kind in North Carolina could include a broader composition of older adults and physicians throughout various counties in the state.

\section{CONCLUSIONS}

This study provides information to assist pharmacists in designing MTM programs in the ambulatory setting. Key attributes of an effective program include one that is comprehensive, addressing all of the patients' medication-related needs over time. The ability of the clinical pharmacist to build trusting relationships with both patients and providers is essential.

\section{Acknowledgments}

This study was supported through funding from the National Institutes of Health, National Institute on Aging (Principal Investigator: 5K23AG024229-04 Research and Career Development Award) to MR and through a Veteran's Affairs Health Services Research \& Development Career Scientist Award to MW (RCS 91-408).

\section{Appendix. A focus group study of medication management in older adults discussion guide}

\begin{tabular}{|l|l|}
\hline Key Areas & Facilitator questions \\
\hline Introduction & $-\quad \begin{array}{l}\text { One of the terms some people use when they talk about medication use is "Medication } \\
\text { management." It may be a term that you may or may not have heard before. Now, if }\end{array}$
\end{tabular}




\begin{tabular}{|l|l|l|}
\hline Key Areas & Facilitator questions \\
\hline Key Questions & $\begin{array}{l}\text { Older Adults } \\
\text { someone were to talk to you about how you "manage your medications," what does this } \\
\text { mean to you? }\end{array}$ \\
- & $\begin{array}{l}\text { For those of you have interacted with a clinical pharmacist tell me about this experience? } \\
\text { What did you like about the interaction and/or the service provided? How does he/she } \\
\text { help you with your medications? } \\
\text { What do you think about having a clinical pharmacist sit down and review with you all of } \\
\text { your medications (prescriptions, herbals, over-the-counter meds) to learn how you are } \\
\text { taking them and to go over all of them with you? } \\
\text { What about having a clinical pharmacist talk to your doctor about ways to improve your } \\
\text { medications to make them safer or more effective for you? } \\
\text { What about meeting with a clinical pharmacist every time you had major changes made } \\
\text { to your medications to make sure they are still safe and effective for you? } \\
\text { What about contacting a clinical pharmacist when you are confused about what you are } \\
\text { supposed to be doing or do not understand your medications or need him/her to help you } \\
\text { sort everything out? }\end{array}$ \\
- $\begin{array}{l}\text { For those of you in the Medicare prescription drug program, what about meeting with a } \\
\text { clinical pharmacist every year to make sure you are in the best prescription plan for you? } \\
\text { What would you be willing to pay for this type of service? }\end{array}$ \\
\hline
\end{tabular}

\begin{tabular}{|c|c|}
\hline \multicolumn{2}{|r|}{ Physicians } \\
\hline Key Areas & Facilitator questions \\
\hline Introduction & $\begin{array}{l}\text { My understanding is that all of you have worked with a clinical pharmacist (to varying } \\
\text { degrees) in the outpatient setting to improve your elderly patients' medication use. } \\
\text { Describe your experience, including the type of services provided by the clinical } \\
\text { pharmacist in the outpatient, ambulatory care setting. }\end{array}$ \\
\hline Key Questions & $\begin{array}{l}\text { - What did you like about the interactions or services provided? What worked well? } \\
\text { What did you not like, or what could have been done differently to improve your } \\
\text { interactions with the clinical pharmacist? } \\
\text { How do you think a medication management program that includes a comprehensive } \\
\text { medication review, assessment of patient's medication use and needs, providing proposed } \\
\text { recommendations to you, and personally calling the patient would be for yourself or other } \\
\text { physicians in primary care practice? } \\
\text { - What are some of the good things about this program? } \\
\text { - What might be some of the potential problems? }\end{array}$ \\
\hline
\end{tabular}

\section{REFERENCES}

1. McGlynn EA, Asch SM, Adams J, et al. The quality of health care delivered to adults in the United States. N Eng J Med. 2003; 348:2635-45.

2. Shrank WH, Asch SM, Adams J, et al. The quality of pharmacologic care for adults in the United States. Med Care. 2006; 44:936-45. [PubMed: 17001265]

3. Law AV, Ray MD, Knapp KK, Balesh JK. Unmet needs in the medication use process: perceptions of physicians, pharmacists, and patients. J Am Pharm Assoc. 2003; 43:394-402.

4. Higashi T, Shekelle PG, Solomon DH, et al. The quality of pharmacologic care for vulnerable older patients. Ann Intern Med. 2004; 140:714-20. [PubMed: 15126255] 
5. Vogeli C, Shields AE, Lee TA, et al. Multiple chronic conditions: prevalence, health consequences, and implications for quality, care management, and costs. J Gen Intern Med. 2007; 22(Suppl 3): 391-5. [PubMed: 18026807]

6. Avorn J. Medication use in older patients: better policy could encourage better practice. JAMA. 2010; 304:1606-7. [PubMed: 20940388]

7. Wenger NS, Solomon DH, Roth CP, et al. The quality of medical care provided to vulnerable community-dwelling older patients. Ann Intern Med. 2003; 139:740-7. [PubMed: 14597458]

8. Stranges, E.; Stocks, C. [Accessed October 19, 2011] Potentially Preventable Hospitalizations for Acute and Chronic Conditions. 2008. [online]. Available at: http://www.hcup-us.ahrq.gov/reports/statbriefs/sb99.jsp.

9. Chisholm-Burns MA, Kim Lee J, Spivey CA, et al. US pharmacists' effect as team members on patient care: systematic review and meta-analyses. Med Care. 2010; 48:923-33. [PubMed: 20720510]

10. Hanlon JT, Weinberger M, Samsa GP, et al. A randomized, controlled trial of a clinical pharmacist intervention to improve inappropriate prescribing in elderly outpatients with polypharmacy. Am J Med. 1996; 100:428-37. [PubMed: 8610730]

11. Wagner EH. The role of patient care teams in chronic disease management. BMJ. 2000; 320:56972. [PubMed: 10688568]

12. Medicare Payment Advisory Commission. [Accessed October 19, 2011] Report to the Congress. Aligning Incentives in Medicare. June. 2010 [online]. Available at: http://www.ncrponline.org/PDFs/2010/MEDPAC_Congress_June2010.pdf.

13. Medication therapy management services: a critical review. J Am Pharm Assoc. 2005; 45:580-7.

14. Devine EB, Hoang S, Fisk AW, Wilson-Norton JL, Lawless NM, Louie C. Strategies to optimize medication use in the physician group practice: the role of the clinical pharmacist. J Am Pharm Assoc. 2009; 49:181-91.

15. Morgan, DL.; Kruger, RA. The Focus Group Tool Kit. Sage Publications, Inc; Thousand Oaks, CA: 1998.

16. Draucker CB, Martsolf DS, Ross R, Rusk TB. Theoretical sampling and category development in grounded theory. Qual Health Res. 2007; 17:1137-48. [PubMed: 17928484]

17. Ulin, PR.; Robinson, ET.; Tolley, EE. Qualitative methods in public health: a field guide in qualitative research. Family Health International; San Francisco, CA: 2005.

18. Roth MT, Moore CG, Ivey JL, Esserman DA, Campbell WH, Weinberger M. The quality of medication use in older adults: methods of a longitudinal study. Am J Geriatr Pharmacother. 2008; 6:220-33. [PubMed: 19028378]

19. Guba, E. Toward a Methodology of Naturalistic Inquiry in Educational Evaluation. UCLA Center for the Study of Evaluation; Los Angeles, CA: 1978.

20. McGrath SH, Snyder ME, Duenas GG, Pringle JL, Smith RB, McGivney MS. Physician perceptions of pharmacist-provided medication therapy management: qualitative analysis. $\mathrm{J} \mathrm{Am}$ Pharm Assoc. 2010; 50:67-71.

21. Kellerman R, Kirk L. Principles of the patient-centered medical home. Am Fam Physician. 2007; 76:774-5. [PubMed: 17910291]

22. Roth MT, Zlatic TD. Development of student professionalism. Pharmacotherapy. 2009; 29:749_ 56. [PubMed: 19476426]

23. Barnett MJ, Frank J, Wehring H, et al. Analysis of pharmacist-provided medication therapy management (MTM) services in community pharmacies over 7 years. J Manag Care Pharm. 2009; 15:18-31. [PubMed: 19125547]

24. Chisholm-Burns MA, Graff Zivin JS, Lee JK, et al. Economic effects of pharmacists on health outcomes in the United States: A systematic review. Am J Health Syst Pharm. 2010; 67:1624-34. [PubMed: 20852164] 


\section{Table 1}

Demographics of Participants ( $\mathrm{N}=28)$; Number (\%)

\begin{tabular}{ll}
\hline Age, mean & 77.7 \\
Female, $\mathrm{n}(\%)$ & $23(82)$ \\
Race, $\mathrm{n}(\%)$ & \\
Whites & $18(64)$ \\
Blacks & $10(36)$ \\
Highest level of education, $\mathrm{n}(\%)$ & \\
Elementary/technical school & $2(7)$ \\
Some high school & $5(18)$ \\
High school graduate & $7(25)$ \\
Some college & $5(18)$ \\
College graduate & $6(21)$ \\
Postgraduate work & $3(11)$ \\
Lives alone, $\mathrm{n}(\%)$ & $19(68)$ \\
Number of physicians, $\mathrm{n}(\%)$ & \\
1 & $4(14)$ \\
2 to 5 & $19(68)$ \\
5 or more & $5(18)$ \\
Number of medications, $\mathrm{n}(\%)$ & \\
5 or less & $6(21)$ \\
$6-10$ & $10(36)$ \\
$11-15$ & $6(21)$ \\
16-20 & $6(21)$ \\
Type of prescription insurance, $\mathrm{n}(\%)$ \\
Medicaid & $3(11)$ \\
Medicare Part D & $16(57)$ \\
Private insurance & $16(57)$ \\
Veterans Affairs benefits & $3(11)$ \\
\hline & $1(4)$ \\
\hline
\end{tabular}

* May not add to $100 \%$ because participants could report more than one type of insurance 
Table 2

Demographics of Physicians (N=8); Number (\%)

\begin{tabular}{ll}
\hline Years in practice, average & 18 (range $5-33)$ \\
Male, n $(\%)$ & $6(75)$ \\
Specialty training ${ }^{*}$ & \\
Geriatrics & $4(50)$ \\
Internal Medicine & $6(75)$ \\
Family Medicine & $1(13)$ \\
Time spent in outpatient care $(\%)$ & \\
$\leq 10 \%$ & 0 \\
$11-25 \%$ & $1(13)$ \\
$26-49 \%$ & $2(25)$ \\
$50-75 \%$ & $4(50)$ \\
$>75 \%$ & $1(13)$ \\
Patients seen by physician who are 65 years of age or older $(\%)$ \\
$\leq 10 \%$ & $1(13)$ \\
$11-25 \%$ & 0 \\
$26-49 \%$ & $1(13)$ \\
$50-75 \%$ & $3(38)$ \\
$>75 \%$ & $3(38)$ \\
\hline
\end{tabular}

May not add to $100 \%$ because physicians could report more than one area of specialty training 
Table 3

Emergent themes and key words and phrases for designing an effective medication management program

\begin{tabular}{|c|c|c|}
\hline Study objective & \multicolumn{2}{|l|}{ Themes and supporting key words and phrases } \\
\hline $\begin{array}{l}\text { Explore older adults' } \\
\text { experiences working with } \\
\text { a clinical pharmacist in } \\
\text { managing their multiple } \\
\text { medications }\end{array}$ & \multicolumn{2}{|l|}{$\begin{aligned} \text { Themes: } & \text { Professional, personable } \\
\text { - } & \text { Professional nature } \\
\text { - } & \text { Resourceful } \\
\text { - } & \text { Personable } \\
\text { - } & \text { Knowledgeable } \\
\text { - } & \text { Approachable } \\
\text { - } & \text { Accessible } \\
\text { - } & \text { Comprehensive } \\
\text { - } & \text { Complements physicians }\end{aligned}$} \\
\hline $\begin{array}{l}\text { Explore physician } \\
\text { perspectives on the role of } \\
\text { clinical pharmacists in } \\
\text { facilitating medication } \\
\text { management }\end{array}$ & \multicolumn{2}{|c|}{ 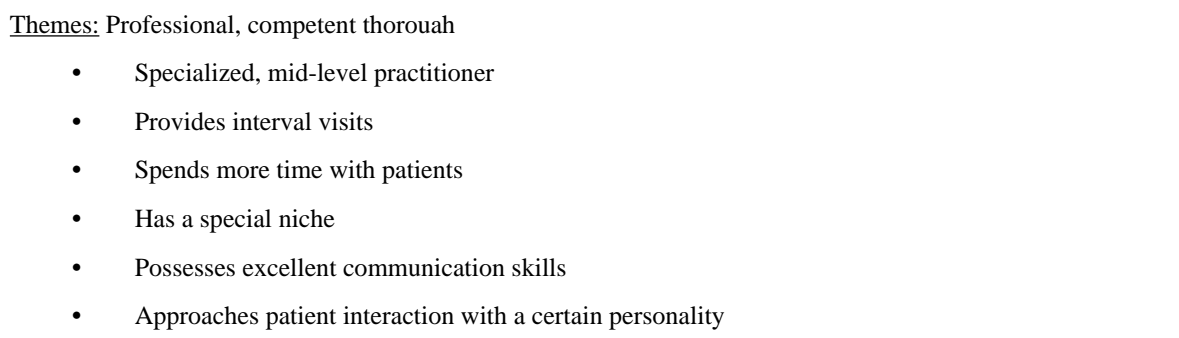 } \\
\hline $\begin{array}{l}\text { Explore key attributes of } \\
\text { an effective MTM } \\
\text { program from the } \\
\text { perspective of both } \\
\text { patients and providers }\end{array}$ & $\begin{array}{l}\text { Older adults } \\
\text { Themes: Team-based, personalized care, } \\
\text { comprehensive } \\
\text { - } \quad \text { Establish team effort and trust } \\
\text { - } \quad \text { Develop personal relationship with } \\
\text { the pharmacist } \\
\text { - } \quad \text { Provide personalized care } \\
\text { - Review medications and determines } \\
\text { - } \\
\text { - } \text { Reffectiveness prescriptions } \\
\text { - } \quad \text { Intercede with health plans } \\
\text { - } \quad \text { Macilitate care during trips } \\
\text { Main contact with family }\end{array}$ & $\begin{array}{l}\text { Physicians } \\
\text { Themes: Trustina relationship, effective communication, } \\
\text { comprehensive } \\
\text { - Develop mutual relationship of trust } \\
\text { - Interact directly with providers } \\
\text { - } \quad \text { Provide patient-centered care and value-added } \\
\text { services } \\
\text { - Develop familiarity with patient history } \\
\text { - Conduct a comprehensive service - more than } \\
\text { a medication review } \\
\text { Target specific populations (including lower } \\
\text { socioeconomic status, high co-morbidities, } \\
\text { complex regimens) }\end{array}$ \\
\hline $\begin{array}{l}\text { Explore potential barriers } \\
\text { from the perspective of }\end{array}$ & $\begin{array}{l}\text { Themes: Perceived need, cost of service } \\
\text { - } \quad \text { Perceived lack of need for additional } \\
\text { assistance } \\
\text { - } \quad \text { Out-of-pocket costs } \\
\text { - } \quad \text { Availability of a pharmacist }\end{array}$ & $\begin{array}{l}\text { Themes: Target population, poor communication, unclear } \\
\text { service model } \\
\text { - Receiving too many and unfocused } \\
\text { recommendations } \\
\text { - Make inappropriate medical assessments } \\
\text { - Access to the medical record } \\
\text { - Undefined role on the patient care team } \\
\text { - Poor communication } \\
\text { - Providing services to untargeted populations }\end{array}$ \\
\hline
\end{tabular}




\begin{tabular}{l|l|l|}
\hline Study objective & Themes and supporting key words and phrases \\
\hline $\begin{array}{l}\text { both patients and } \\
\text { providers }\end{array}$ & $\bullet \begin{array}{l}\text { Inconvenient payment structure for } \\
\text { services }\end{array}$ & $\bullet \quad$ Uncertain payment for services \\
\hline
\end{tabular}

